\title{
Multi-mode Polymerizations Involving Photoinduced Radical Polymerization
}

\author{
Görkem Yılmaz ${ }^{1}$ and Yusuf Yagci ${ }^{12^{*}}$ \\ ${ }^{1}$ Istanbul Technical University, Department of Chemistry, Maslak, Istanbul 34469, Turkey \\ ${ }^{2}$ Faculty of Science Chemistry Department, King Abdulaziz University, Jeddah 21589, \\ Saudi Arabia \\ *yusuf@itu.edu.tr
}

\begin{abstract}
Multi-mode polymerizations provide a facile route to synthesis of block and graft copolymers that cannot be made by a single polymerization mode. In such strategy, photoinduced free radical polymerization as one of the polymerization mode play a crucial role due to its simplicity, wavelength flexibility, applicability to wide range of monomers and minimized side reactions. In this article, various combinations of photoinduced conventional and controlled/living radical polymerizations with other polymerization methods, namely cationic, free radical promoted cationic, ring opening, and ring opening metathesis polymerizations are presented and mechanistic details are evaluated. Moreover, the possibilities for the simultaneous or sequential processes are discussed.

Keywords: Multimode polymerization, Photopolymerization, Radical polymerization, Cationic polymerization, Ring opening polymerization
\end{abstract}

\section{Introduction}

Photoinitiated polymerizations are the distinguished processes that transform a monomer into a polymer by the use of the incident photon energy. Both addition and step-growth polymerizations can be performed by photochemical means, though the former was more intensively investigated [1,2]. Photoinduced radical and cationic polymerizations are well-known and applied to numbers commercial applications due to the availability of a variety of photoinitiators available [3]. Therefore, photoinitiators are the key elements for the polymerization to occur. Upon light exposure, these photoinitiators yield reactive species that initiates polymerization of appropriate monomers. These systems offer several advantages such as rapid reaction rates, reduced energy consumptions, mild temperatures and decreased probability of transfer reactions in comparison to thermal techniques. In addition, light induced processes generate reactive species at definite position of the macromolecular chains and surfaces, which allow the preparation of polymeric materials with specified structural compositions.

Photopolymerizations have been adapted to the syntheses of various macromolecular structures. The mild nature of photopolymerizations provide their combinations with other modes of polymerizations for such polymer syntheses. This way, combination of attractive properties of the polymers of structurally diverse monomers, which are polymerizable by different mechanisms, can be attained. The present article will focus on multimode polymerizations involving photoinduced radical polymerization technique as one of the modes for complex macromolecular syntheses. A special emphasize will be devoted on the recent developments.

\section{Photoinduced polymerization}

\subsection{Photoinduced radical polymerization}

Photoinduced radical polymerizations can be performed by using radical photoinitiators, which are generally classified into two groups, namely Type I (cleavage type) and Type II (hydrogen abstraction). Type $I$ initiators photochemically decompose upon light irradiation to yield two different radicals (unless the structure has a symmetry axis), both capable of initiating polymerization [4-7]. The well-known Type I 
photoinitiators are 2,2-dimethoxy-2phenylacetophenone (DMPA) (Scheme 1), 2hydroxy-2-methylpropiophenone, and bisacylphosphine oxide.

Type / Photoinitiators ( $\alpha$-Cleavage)

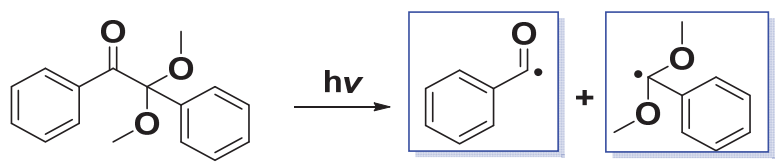

Scheme 1. Mechanism of photoinduced radical generation using 2,2-dimethoxy-2-phenylacetophenone.

Type II photoinitiators on the other hand require an additional co-initiator in the system to initiate the polymerization. Such co-initiators function as means of electron or hydrogen donors, which provide the formation of radicals responsible for the initiation of polymerization. Typical Type II initiators include benzophenone, thioxanthone derivatives, and camphorquinone, which are generally used together with amines, thiols, ethers or alcohols as co-initiators. Notably, latest reports demonstrate the possibility of employing novel Type II initiators with one component nature, possessing both the light harvesting chromophore and the hydrogen donating functions [8-17]. Scheme 2 demonstrates the radical generation mechanism on the example of thioxanthone.

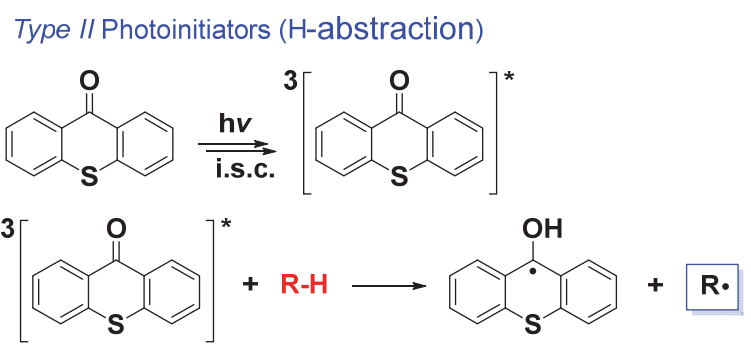

R-H: amines, thiols, ethers, alcohols

Scheme 2. Mechanism of photoinduced radical generation using thioxanthone.

There are also other photoinitiation methods for radical polymerization. One of the most intensively used method is undoubtedly the use of manganese decacarbonyl $\left(\mathrm{Mn}_{2}(\mathrm{CO})_{10}\right)$ together with alkyl halides. The pair yields reactive alkyl radicals upon visible light irradiation [18-24].

\subsection{Photoinduced cationic polymerizations}

Photoinduced cationic polymerizations can be initiated by the onium salts as discovered by
Crivello about four decades ago. The common examples are diphenyliodonium, triphenylsulfonium and $N$-alkoxy pyridinium salts with non-nucleophilic counter ions such as hexafluorophosphate and hexafluoroantimonate to prevent termination reaction [3,25-28]. Scheme 3 presents the photoinduced cationic polymerization mechanism using onium salts as initiators. Recent developments demonstrate the possibility of conducting cationic polymerizations with diphenyliodonium iodide/zinc halide couple, where the nucleophilic nature of the anion is balanced by the zinc based Lewis acids [29-32].

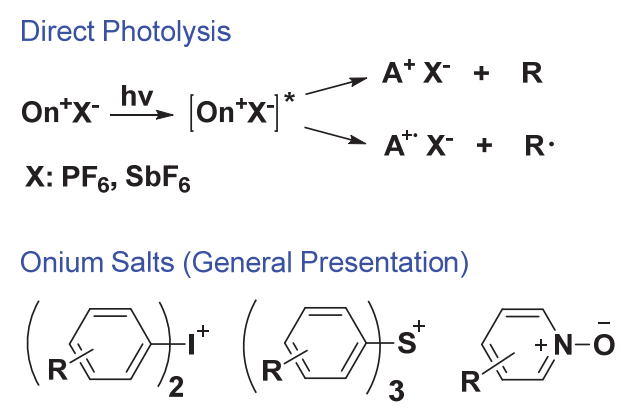

Scheme 3. Mechanism of photoinduced cationic polymerization using typical onium salts.

\section{Combination of photoinduced polymerizations with other modes of polymerizations}

As stated above, mechanistic transformation is an elegant approach to combine different modes of polymerizations for the syntheses of complex polymeric structures, which cannot be prepared by employing only a single polymerization mechanism [33]. Photoinduced polymerizations are successfully combined with other polymerization modes to synthesize block and graft copolymers.

3.1. Combination of photoinduced radical polymerization with traditional polymerization modes

Early examples of multimode polymerizations employing photochemical approaches are based on the preparation of polymeric photoinitiators. This way, polymers possessing photo-labile chain-end functionalities can be prepared. Afterwards, thus obtained polymers can be exposed to UV irradiation to produce radicals at their chain ends that is capable of initiating free radical polymerization. To exemplify, a specifically designed compound having both thermally and photochemically active centers is a useful tool for the application of strategy [34-37]. Yagci and co-workers developed an azobenzoin compound possessing both benzoin and 
diazo-groups in the structure. The thermal decomposition of the azo group in the presence of a monomer provides attachment of thermally stable benzoin groups to polymer chain ends, which can further be used for the subsequent photopolymerization. Since the termination step is preferably by recombination in the case of styrene polymerization, this method yields polystyrene with benzoin functionalities at both chain ends. As such, triblock copolymers can be synthesized when this polymer is used as a macroinitiator for photopolymerization (Scheme 4).

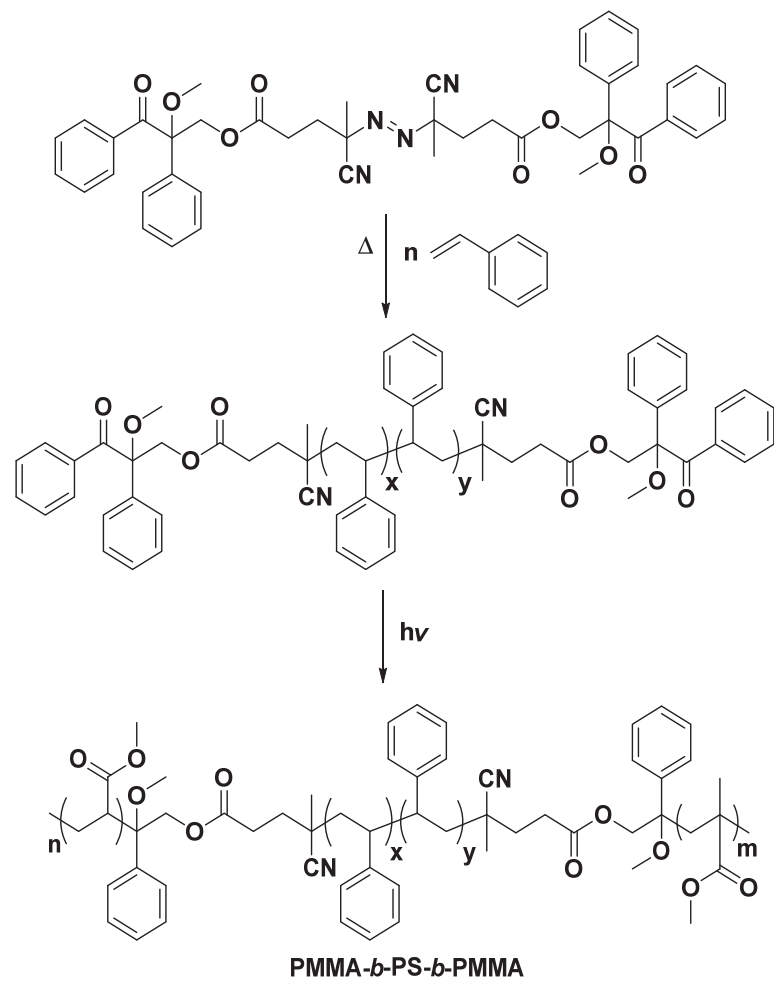

Scheme 4. Synthesis of block copolymers by the combination of thermally and photochemically induced radical polymerization by $\alpha$-cleavage.

In another strategy, diazo-initiators bearing coinitiator functionalities were also designed and synthesized. This way, after a conventional thermally induced radical polymerization, macroinitiators having hydrogen donating sites at both $\alpha$ and $\omega$ sites can be prepared. Thus obtained macroinitiators yield triblock copolymers when treated with Type II initiators under light irradiation (Scheme 5).

Alternative approach considers the synthesis of macroinitiators, by taking the advantage of using co-initiators bearing chromophore groups. In a previous work, epiclorohydrin was polymerized by activated monomer mechanism using a photoactive group bearing hydroxyl functionality [38]. This way, polyepichlorohydrine having photoinitiator moiety at the chain-end was prepared, which was employed as a macroinitiator for photopolymerization in a similar manner that described above (Scheme 6).

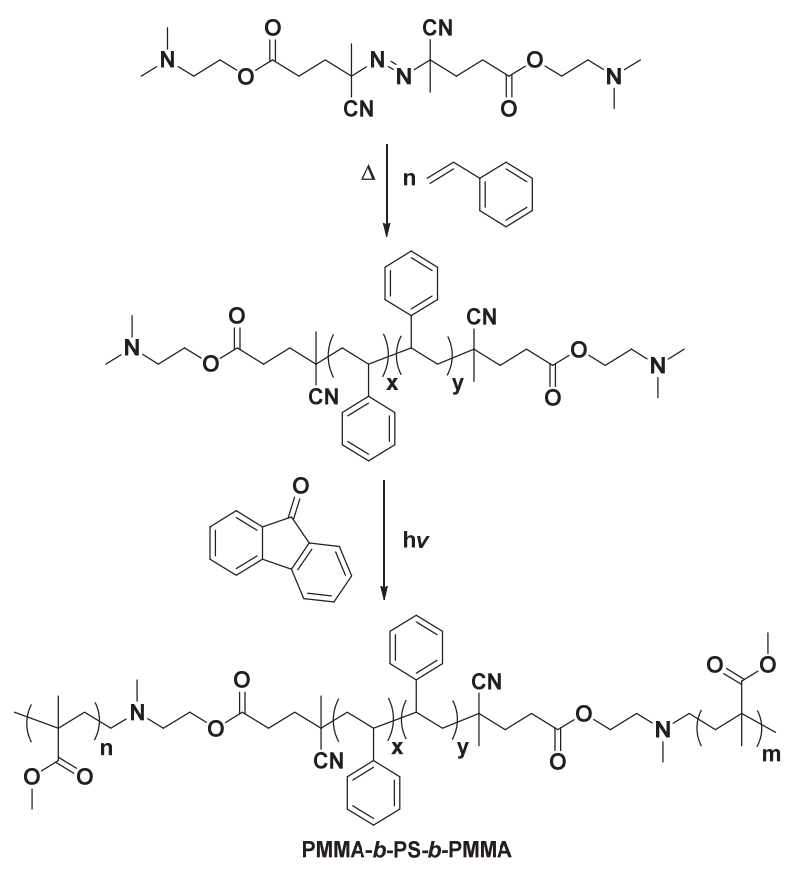

Scheme 5. Synthesis of block copolymers by the combination of thermally and photochemically induced radical polymerization by hydrogen abstraction.<smiles>O=C(c1ccccc1)C(O)c1ccccc1</smiles><smiles>O=C(Cl)OC(C(=O)c1ccccc1)c1ccccc1</smiles>

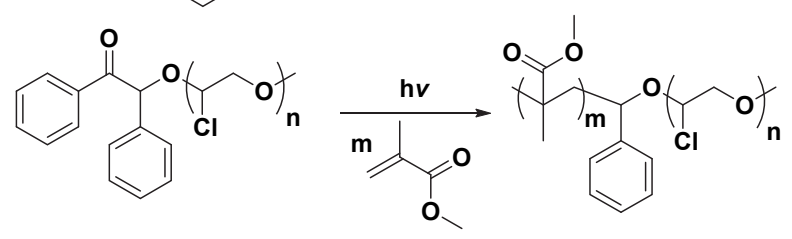

Scheme 6. Synthesis of block copolymers by the combination of activated monomer cationic polymerization with photoinduced radical polymerization.

Such polymeric photoinitiators can also be synthesized by using a specific termination agent that displays photoactivity [39]. For example, termination of a living polytetrahydrofuran (PTHF) with sodium salt of benzoin gives a photoactive PTHF. Photolysis of either $\alpha$ or $\alpha$, $\omega$-benzoin terminated PTHF in the presence of a free radical 

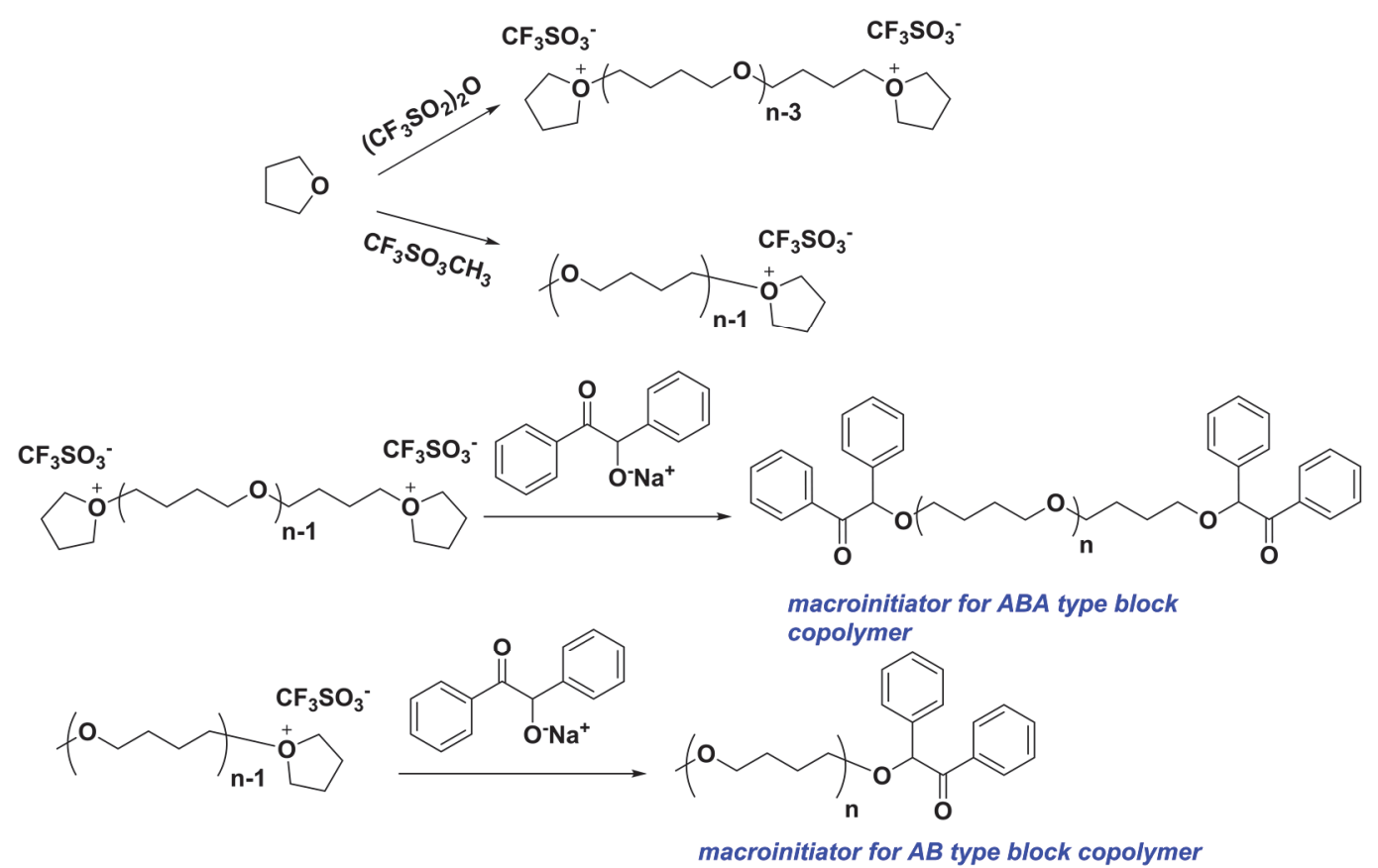

Scheme 7. Synthesis of PTHF-based macroinitiators for free radical polymerization.

polymerizable monomer yields $\mathrm{AB}$ and/or $\mathrm{ABA}$ type block copolymers, respectively (Scheme 7).

$\mathrm{N}$-Alkoxypyridium salts can also be used as terminating agents in THF polymerization in order to incorporate photoinitiator functionality at the chain ends. Thus obtained $\mathrm{N}$-alkoxy pyridinium chain-end terminated PTHF can be used as macroinitiators, which yield block copolymers after photopolymerization [40].

3.2. Combination of photoinduced radical polymerization with controlled/living polymerizations (CLP)

Photoinduced radical polymerization can be combined with CLP techniques, which offer more precise functional group control. For example, atom transfer radical polymerization (ATRP) and ring opening polymerization (ROP) are useful tools for such combinations that can be realized by using specifically designed dual initiators. For this purpose, a compound possessing both ATRP or ROP initiating sites and a photolabile group were successfully used for block copolymer syntheses [41-43]. A typical example on such combination is presented in Scheme 8.

We have also shown that ATRP could be combined with $\mathrm{Mn}_{2}(\mathrm{CO})_{10}$ assisted photoinitiated radical polymerization for block copolymer synthesis $[44,45]$. Because that the second segment could be constructed by radical polymerization but not ATRP, the strategy was shown to be useful for such block copolymer syntheses. In addition, it was also demonstrated that the radical produced at the chain end could be oxidized and cationic polymerization of structurally appropriate monomers could be initiated from this site to form block copolymer (Scheme 9).

In a typical study it was also shown that Ring

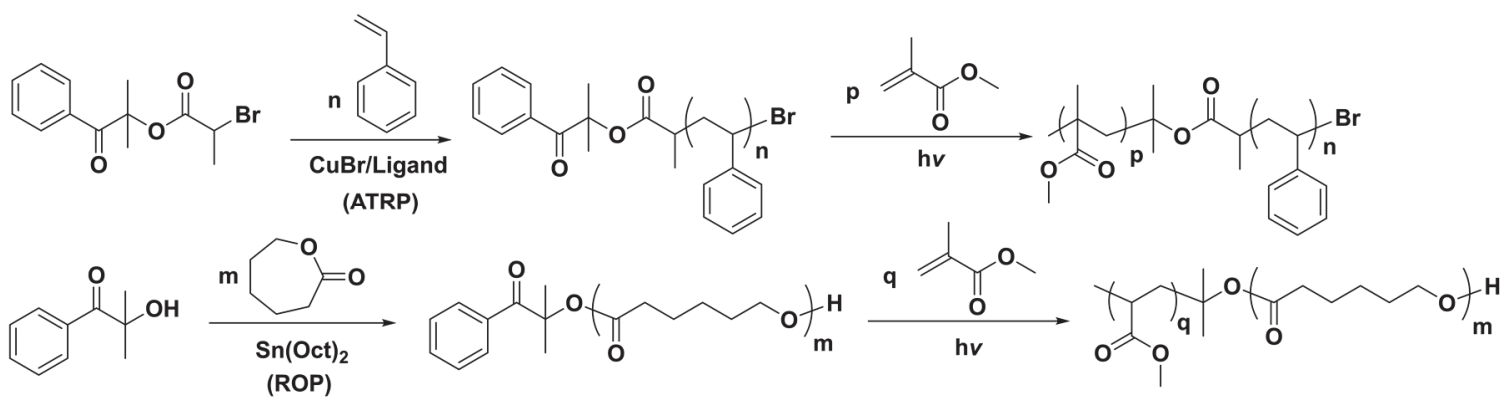

Scheme 8. Synthesis of block copolymers by the combination of ATRP and ROP with photoinduced radical polymerization. 


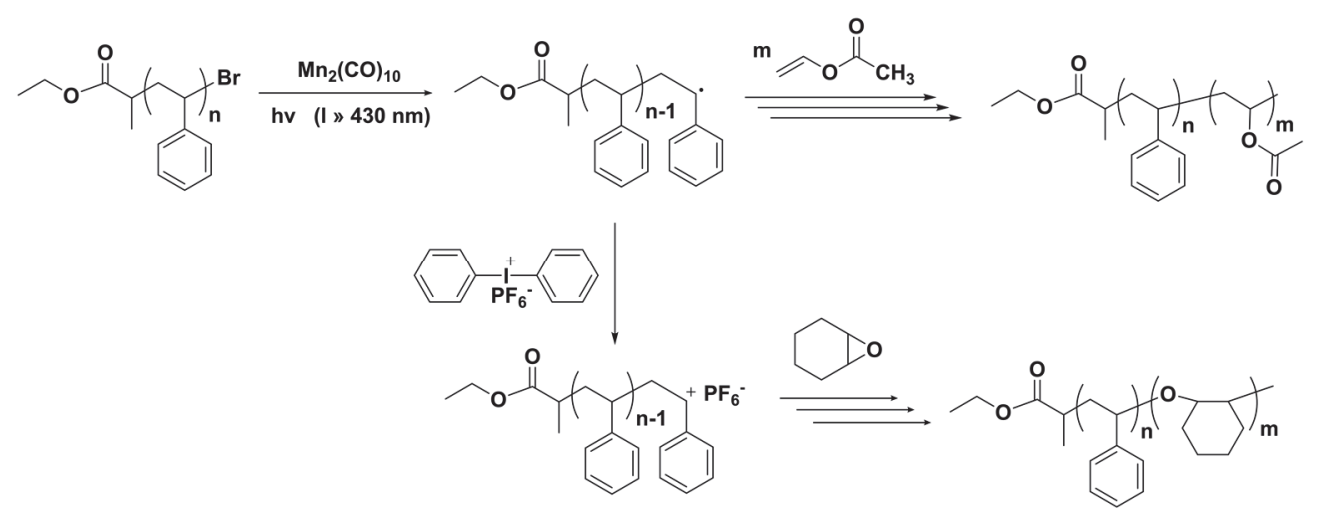

Scheme 9. Combination of ATRP with $\mathrm{Mn}_{2}(\mathrm{CO})_{10}$ photochemistry for block copolymer syntheses.

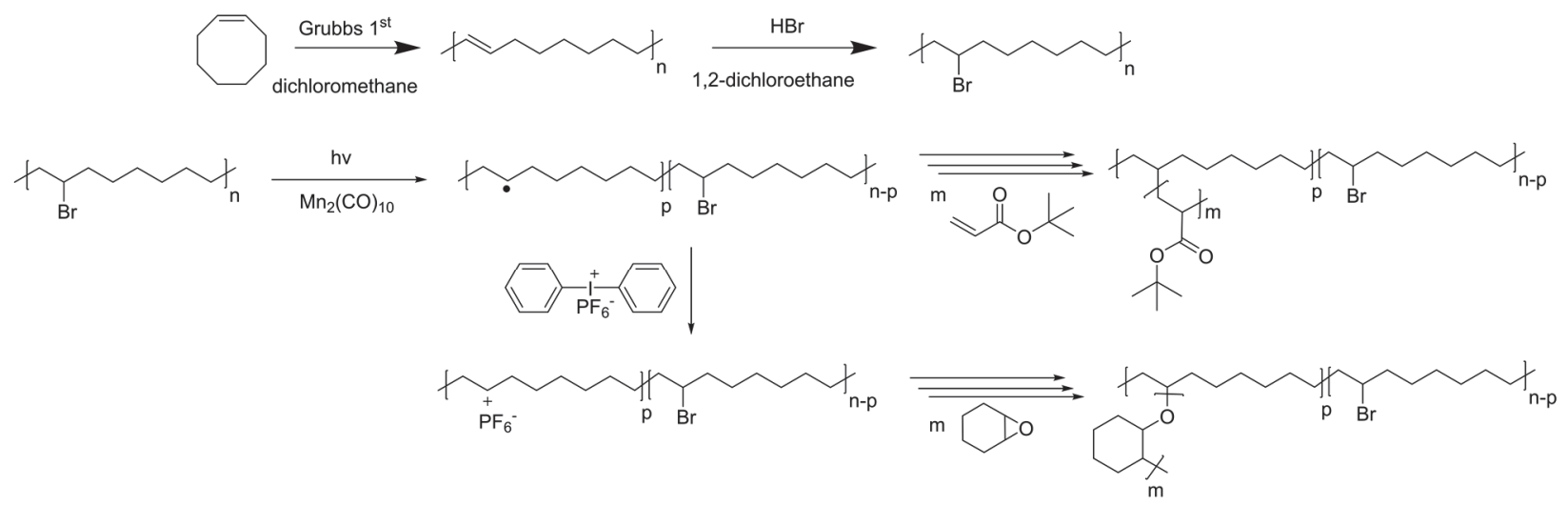

Scheme 10. Combination of ROMP with $\mathrm{Mn}_{2}(\mathrm{CO})_{10}$ photochemistry for graft copolymer syntheses.

Opening Metathesis Polymerization (ROMP) can be combined with $\mathrm{Mn}_{2}(\mathrm{CO})_{10}$ photochemistry for graft copolymer syntheses [46]. For this purpose, cis-cyclooctene was polymerized via ROMP in the presence of a chain transfer agent and quantitatively hydrobrominated to give bromo functional polyethylene (PE-Br). Subsequent irradiation of $\mathrm{PE}-\mathrm{Br}$ using $\left(\mathrm{Mn}_{2}(\mathrm{CO})_{10}\right)$ yielded pendant radicals on PE chain, which can be used for both radical and free radical promoted cationic polymerizations essentially to yield respective graft copolymers (Scheme 10).

Similar to the methodology described above, pyridine $N$-oxide can also be used to functionalize main- and side-chain halogen containing polymers obtained by ATRP and nitroxide mediated polymerization, respectively [47,48]. A simple substitution of the halide groups, with $\mathrm{N}$-alkoxy chromophores yield photoactive polymers that can be used for block and graft copolymer syntheses as

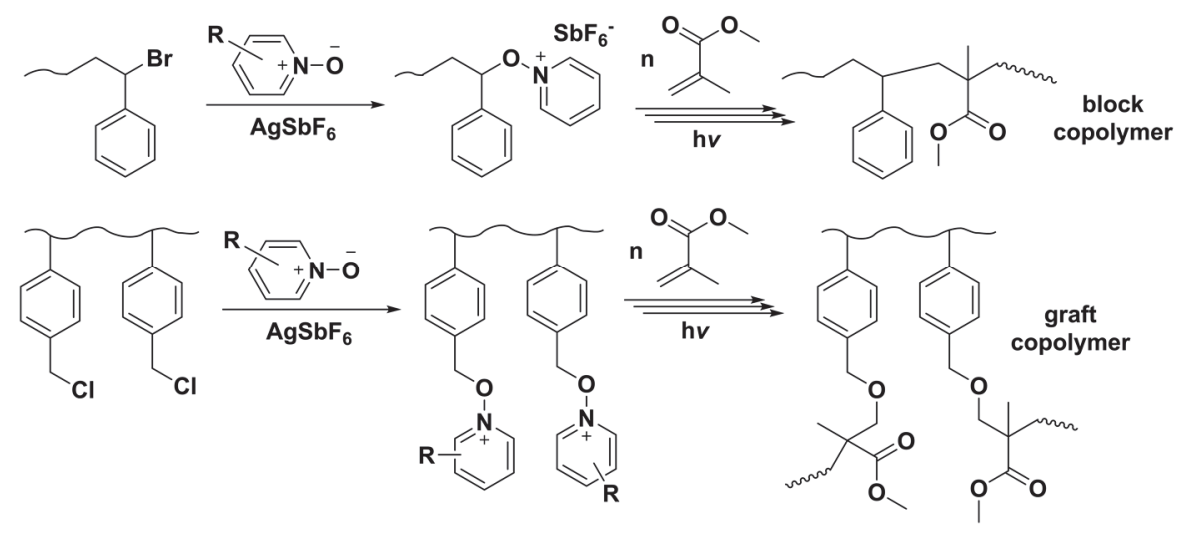

Scheme 11. Preparation of block and graft copolymers by ATRP/photopolymerizaiton and NMP/photopolymerization combinations. 


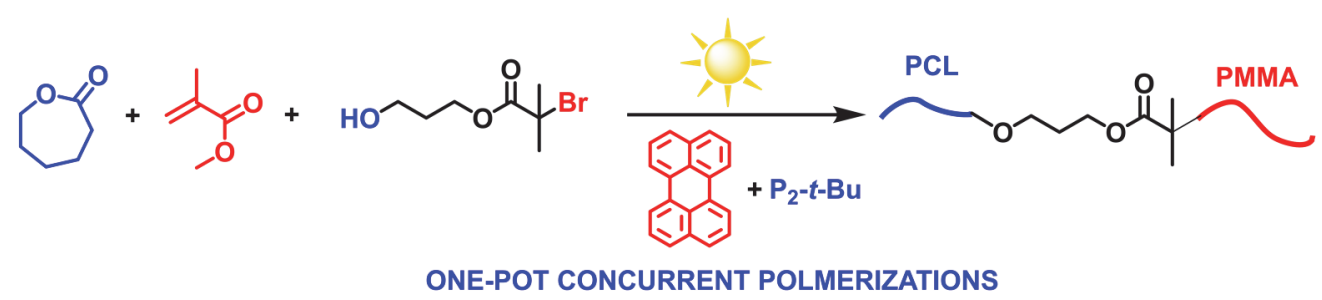

Scheme 12. Synthesis of block copolymers by the simultaneous combination of photoinduced metal-free ATRP and ROP.

shown in Scheme 11.

Notably, photoinduced radical generation processes can also be combined with CLP techniques for the preparation of telechelic polymers and structurally more complex macromolecules [49].

Recent advances show that ATRP could readily be accomplished under completely metal-free conditions by the employing of photochemical approaches. Certain photoactivators were shown to catalyze ATRP under UV and visible light irradiation even in the absence of copper catalysts. Specifically, phenothiazines, perylene, pyrene, phenoxazines, dihydrophenazines, dye/amine combinations were shown to catalyze metal-free ATRP, when used in the presence of an alkyl halide initiator. This discovery lead to the application of one-pot polymerization combinations by a simultaneous manner for the syntheses of various structures. Yagci and co-workers demonstrated the possibility of realizing photoinduced metal-free ATRP and ring opening polymerizations (ROP) in a concurrent fashion [50]. Thus, block copolymers were synthesized in a simple and efficient way (Scheme 12). Notably, same strategy could not be applied using conventional ATRP and ROP processes as the required metal-catalysts undergo a redox reaction as previously reported.

Provided that proper chemical structures are selected, similar strategy can be applied also for the synthesis of graft copolymers. Studies conducted in our laboratory revealed that the aforementioned concurrent combinations afford successful graft copolymer syntheses with functional group control and narrow molecular weight distributions.

\section{Conclusion}

This study clearly demonstrates that the application of multi-mode polymerizations involving photoinduced free radical polymerization as one of the applied mode is a versatile methodology for the fabrication wide range of macromolecular. The methodology also provides possibility to benefit from the properties of the structurally different polymers that can not be realized just by applying particular polymerization mode. Considering the facile polymer synthesis in a simple way, this multi-mode concept could have potential in the preparation of various macromolecular architectures with desired properties for specific applications.

\section{References}

1. Y. Yagci, S. Jockusch, and N. J. Turro, Macromolecules, 43 (2010) 6245.

2. J. V. Crivello, K. Dietliker, G. Bradley, and S. T. Limited, Chemistry \& technology of $U V \&$ EB formulation for coatings, inks \& paints, 1998.

3. J. V. Crivello, J. Polym. Sci., Part A: Polym. Chem., 37 (1999) 4241.

4. J. Jakubiak, X. Allonas, J. P. Fouassier, A. Sionkowska, E. Andrzejewska, L. A. Linden, and J. F. Rabek, Polymer, 44 (2003) 5219.

5. K. Dietliker, R. Husler, J. L. Birbaum, S. Ilg, S. Villeneuve, K. Studer, T. Jung, J. Benkhoff, H. Kura, A. Matsumoto, and H. Oka, Prog. Org. Coat., 58 (2007) 146.

6. K. Dietliker, T. J. Jung, J. Benkhoff, H. Kura, A. Matsumoto, H. Oka, D. Hristova, G. Gescheidt, and G. Rist, Makromol. Chem. Macromol. Symp., 217 (2004) 77.

7. W. Rutsch, K. Dietliker, D. Leppard, M. Kohler, L. Misev, U. Kolczak, and G. Rist, Prog. Org. Coat., 27 (1996) 227.

8. M. Aydin, N. Arsu, and Y. Yagci, Macromol. Rapid Commun., 24 (2003) 718.

9. M. Aydin, N. Arsu, Y. Yagci, S. Jockusch, and N. J. Turro, Macromolecules, 38 (2005) 4133.

10. D. K. Balta, N. Arsu, Y. Yagci, S. Jockusch, and N. J. Turro, Macromolecules, 40 (2007) 4138.

11. L. Cokbaglan, N. Arsu, Y. Yagci, S. Jockusch, and N. J. Turro, Macromolecules, 36 (2003) 2649. 
12. G. Temel, B. Aydogan, N. Arsu, and Y. Yagci, Macromolecules, 42 (2009) 6098.

13. G. Yilmaz, B. Aydogan, G. Temel, N. Arsu, N. Moszner, and Y. Yagci, Macromolecules, 43 (2010) 4520.

14. G. Temel, N. Arsu, and Y. Yagci, Polym. Bull., 57 (2006) 51.

15. D. Tunc and Y. Yagci, Polym. Chem., 2 (2011) 2557.

16. G. Yilmaz, G. Acik, and Y. Yagci, Macromolecules, 45 (2012) 2219.

17. G. Yilmaz, A. Tuzun, and Y. Yagci, J. Polym. Sci., Part A: Polym. Chem., 48 (2010) 5120.

18. M. Ciftci, M. A. Tasdelen, and Y. Yagci, Polym. Chem., 5 (2014) 600.

19. R. W. Wegman, R. J. Olsen, D. R. Gard, L. R. Faulkner, and T. L. Brown, J. Am. Chem. Soc., 103 (1981) 6089.

20. H. Yesaka, T. Kobayashi, K. Yasufuku, and S. Nagakura, J. Am. Chem. Soc., 105 (1983) 6249.

21. K. Koumura, K. Satoh, and M. Kamigaito, Macromolecules, 41 (2008) 7359.

22. C. H. Bamford, J. W. Burley, and M. Coldbeck, J. Chem. Soc., Dalton Trans., (1972) 1846.

23. C. H. Bamford and R. Denyer, Nature, 217 (1968) 59.

24. C. H. Bamford and M. U. Mahmud, J. Chem. Soc., Chem. Commun., (1972) 762.

25. Y. Yagci and I. Reetz, Prog. Polym. Sci., 23 (1998) 1485.

26. J. V. Crivello, Adv. Polym. Sci., 62 (1984) 1.

27. J. V. Crivello and J. H. W. Lam, Macromolecules, 10 (1977) 1307.

28. Y. Yagci, A. Kornowski, and W. Schnabel, J. Polym. Sci., Part A: Polym. Chem., 30 (1992) 1987.

29. M. U. Kahveci, M. Uygun, M. A. Tasdelen, W. Schnabel, W. D. Cook, and Y. Yagci, Macromolecules, 42 (2009) 4443.

30. M. U. Kahveci, M. A. Tasdelen, and Y. Yagci, Polymer, 48 (2007) 2199.

31. M. U. Kahveci, F. Oytun, and Y. Yagci, Polymer, 54 (2013) 4798.
32. M. U. Kahveci, M. A. Tasdelen, and Y. Yagci, Macromol. Rapid Commun., 29 (2008) 202.

33. Y. Yagci and M. A. Tasdelen, Prog. Polym. Sci., 31 (2006) 1133.

34. Y. Hepuzer, M. Bektas, S. Denizligil, A. Onen, and Y. Yagci, J. Macromol. Sci. Part A Pure Appl. Chem., A30 (1993) 111.

35. A. Onen and Y. Yagci, J. Macromol. Sci., Rev. Macromol. Chem., A27 (1990) 743.

36. A. Onen and Y. Yagci, Angew. Makromol. Chem., 181 (1990) 191.

37. Y. Yagci and A. Onen, J. Macromol. Sci., Rev. Macromol. Chem., A28 (1991) 129.

38. Y. Yagci, Y. Hepuzer, A. Onen, I. E. Serhatli, P. Kubisa, and T. Biedron, Polym. Bull., 33 (1994) 411.

39. A. Onen, Y. Yagci, and W. Schnabel, Angew. Makromol. Chem., 243 (1996) 143.

40. G. Hizal, Y. Yagci, and W. Schnabel, Polymer, 35 (1994) 4443.

41. M. Degirmenci, I. Cianga, and Y. Yagci, Macromol. Chem. Phys., 203 (2002) 1279.

42. Y. Yagci, M. Degirmenci, I. Cianga, and G. Hizal, Abstr. Pap. Am. Chem. S., 224 (2002) U395.

43. S. Yurteri, I. Cianga, M. Degirmenci, and Y. Yagci, Polym. Int., 53 (2004) 1219.

44. G. Acik, M. U. Kahveci, and Y. Yagci, Macromolecules, 43 (2010) 9198.

45. M. U. Kahveci, G. Acik, and Y. Yagci, Macromol. Rapid Commun., 33 (2012) 309.

46. M. Ciftci, M. Arslan, M. Buchmeiser, and Y. Yagci, ACS Macro Lett., 5 (2016) 946.

47. Y. Y. Durmaz, G. Yilmaz, and Y. Yagci, $J$. Polym. Sci., Part A: Polym. Chem., 45 (2007) 423.

48. Y. Y. Durmaz, G. Yilmaz, and Y. Yagci, Macromol. Chem. Phys., 208 (2007) 1737.

49. G. Temel, B. Aydogan, N. Arsu, and Y. Yagci, J. Polym. Sci., Part A: Polym. Chem., 47 (2009) 2938.

50. C. Aydogan, C. Kutahya, A. Allushi, G. Yilmaz, and Y. Yagci, Polym. Chem., 8 (2017) 2899. 